https://doi.org/10.3126/pragya.v7i1.34705

\title{
Role of Private School for Income and Employment Generation in Nepal
}

\begin{abstract}
This paper briefly discusses about the income and generation of employment contributed by the Private Schools in Nepal. The educational system of Nepal includes school education and higher education.In both levels, the role of private education has grown up, promoted and explored by some educational actors as a solution to the lack of sufficient public provision of education or underperforming public schools.Primary source has been used for collection of data. The main purpose of collecting primary data and information at micro level is to understand academic environment, income and employment situation, perception of teachers, and academic facilities with the school of sample schools.There are significant numbers of semi-skilled and unskilled labor force in private schools. Hence school is also providing employment not only to the skilled and educated mass but also to the unskilled and semi-skilled both male and female workers.
\end{abstract}

Keywords: income, private school, employment, education, Nepal

\section{Introduction}

Education is one of the most discussed and most controversial social issues in the World. School choice is a large part of the educational process. Private school students achieve better learning outcome in comparision to the public schools (Ashley et.al, 2014).The role of private education has grown in many parts of the world, and private education is being promoted and explored by some educational actors as a solution to the lack of sufficient public provision of education or underperforming public schools. But the privatizing approach is increasingly being questioned by some educationalists regarding the quality of education, equality of educational opportunities and the availability of free education. Despite the success of institutional schools in quantity and quality, there are problems and challenges as well. Educational management, quality, relevance, and access are some of the critical issues of education in Nepal.

Improvement of quality of education is a challenging task.However, it is impossible without the involvement of private schools (Adhikari and Aryal, 2018). It is obvious that private schools play vital role to educate the nation. The development is synonymous with the ability of a nation to produce quality and quantity of human capital. No doubt the private educational sectors contribute a lot to produce able human resources. This study attempts to 
make an economic inquiry into the existing situation of private schools that is likely to offer an obvious base for the increasement of overall participation in education.

Nepal's educational system is categorized into two: school education and higher education. Up to the beginning of the School Sector Reform Program (SSRP), school education was divided into Early Childhood Education and Development/Pre-Primary Education (ECED/PPE), primary education and secondary education. But under the SSRP a new overall structure was introduced with basic education. Primary education covers grade 1 to 8 and secondary education grades from 9 to 12, amounting to 12 years of formal school education. Currently, basic education includes one year of ECED/PPE and class 1 to 8 and secondary education includes grade 9 to 12 . The intermediate level, which was equivalent to higher secondary level, was also being offered under university education. Higher education consists of three to four year-long bachelor's degrees and two-year masters' degrees. Some universities also offer postgraduate diploma and Master of Philosophy (M. Phil.) courses. The Doctorate of Philosophy (Ph.D.) is the highest degree offered (MoF, 2016).

The technical schools spread across the country that provides short- and long-term training courses on different technical and vocational skill areas. Some of these courses are offered to students studying at the level of Grade-Ten while other courses are for students who have already passed the School Leaving Certificate (SLC) level (MoE, 2010).

Private schools, also known as independent schools or non-state schools, are not administrated by local, state or national government. Hence, they have retained the right to select their students and are funded in whole or in part by charging their students tuition rather than relying on mandatory taxation through public.

\section{Objective}

The main objective of the study is to examine the employment and income generation contributed by the private schools.

\section{Literature Review}

Literature Review is the essential part of discovering what other researchers of the similar field have discovered and are remaining to do for the present and future researchers.

Alghanim (1990) estimated and concluded that score of private school's students are better than the same levels in public schools. This result led to explore the main reasons. The researcher draws the conclusion that the enhanced outcomes in private schools are because of the qualities of teachers found that in private schools. The better preparation of teachers led to the better results of the students. 
Gibson (1993) is another researcher who discussed the main reasons for US parents' choice of a private school. Gibson found that out of various there are two main reasons which are qualifications and the quality of teaching, followed by the quality of the curriculum. The researcher explored the lack of attention of teachers; large class size and perceived poor quality of teaching were main reasons behind the US parents taking their children out of public school.

Lindahl, (2008) concluded the general achievement effects of choice and competition between public and institutional schools in Sweden. For this purpose, the researchers have used administrative data on compulsory school graduates in 1988-2003. The findings are impact of a 10-percentage point increase in the private school share on average 9th-grade GPA is just below one percentile rank point. Nevertheless, it is very stable across specifications and it does not seem to be driven by either differential grade-setting standards or different pre-reform or concurrent trends in unobservable variables across municipalities. The researcher find a positive impact on the fraction of students who chooses an academic high school track and found very little support for that the positive 9th-grade effect also leads to better performance in high school for the same individuals (who enter HS). Moreover, there is no evidence that an increase in private schooling at the compulsory level has an effect on subsequent university attainment or years of schooling. Thus, they concluded that the positive first-order effect on 9th grade performance vanishes over time. It does not seem to be large enough to lead to lasting positive effects. One potential reason for why we find such a small impact is that the entry of new institutional schools not has been followed by the closing down of public schools. Hence, it might be that increasing shares of school budgets have been devoted to maintain operating public schools of poor quality.

Subedi (2013) concluded that the current policy discourse in school education is likely to widen social and economic inequality in Nepalese society, although a considerable proportion of students (more than 20 percent) are in institutional schools. This would inevitably produce a highly segmented and polarized society. Nevertheless, the findings indicate that parents are increasingly aware of the importance of education and are interested to invest a lot in children's education. The privatization of education has spread across society in all classes: rich, middle and even laborer and peasant. The elimination of institutional schools would not be acceptable for many parents and also would not be possible in the context of increasing globalization. Thus, Nepal has to adopt measures that will follow the good practices of institutional schools in public schools and thereby reduce inequality in education. In addition, the government of Nepal needs to come up with a clear plan to utilize the one percent education tax to the benefit of the marginalized people. Finally, both the public and private sectors need to build partnerships with the aim of 
improving the quality of education. The findings from the government side are to formulate separate legislation to regulate institutional schools. It aims to develop separate institutional mechanisms to provide for the registration and monitoring of institutional schools, and provides training to private school's principals and teachers regularly together with public school teachers in order to assist teachers in the licensing exam. Similarly, the findings from the institutional school is to create idea sharing program between private and public schools, to increase the allocation of scholarship seats for girls, members of marginalized communities and students from remote areas to initiate selection of best students to enroll in institutional schools from the countryside from public schools. The findings also attempt to allocate scholarships to children from public schools in remote and disadvantaged areas and cover training cost of teachers.

Yildirim (2013) revealed that education quality and physical conditions were better in private school. However, the private school cannot be regarded to have greater success because they do not compete with equal conditions. Both for-profit and non-profit institutions are still under debate as to whether they could offer solutions to problems of education. As it is seen in the example of Turkey, focusing on public schools would be more promising to achieve quality and equity in education. On the other hand, Turkish institutional schools are vastly profit-making and were founded in response to elite demands. While Turkish government reached the goal of free education for all in primary level, its failure in quality of education was the main cause behind the demand for institutional schools. They are yet very few compared to the public schools. Thus, their economic contribution to the government remains limited. When compared public primary school and private primary schools' physical conditions and students' background were very different from each other. Private school had better conditions and not-surprisingly higher success. In conclusion institutional schools will continue to exist as long as the demand exists. However, privatization does not appear to be promising in the sense of raising the quality of national education. Governments, while taking steps to regulate the existing private institutions, should concentrate on enhancing the adequacy and quality of public education through not only increasing the investments but also improving the system particularly in regard to teachers' quality and motivation. Thus, depleting the demand for institutional schools can be aimed in long term.

Shabbir, et al. (2014) explored a comprehensive study to compare the performance, achievements and effectiveness of government versus private primary schools in rural areas of Azad Jammu and Kashmir. Different measures that focused on overall performance were taken for this comparison. To check the performance of both public and private schools, a survey was conducted through questionnaires for four stakeholders: Head Master, Teachers, Parents and Students. The predominant findings show that Private 
schools perform better than public schools in maximum measures of performance except a few which have been taken in this study, but both public and private schools in Azad Jammu \& Kashmir face a number ofchallenges. Both sectors still deprive of quality of human and material resources for the provision of standard education. The conclusion of the study were Public schools H/Ts are more satisfied by their employments as H/T as compared to private school H/Ts(principals), in fact comparatively reasonable salaries in the public sector by which they enjoyed. Whereas private school principals have an advantage of more satisfaction as compared to public schools $\mathrm{H} / \mathrm{Ts}$ pertaining to cooperation of higher authorities with them, by their teaching staff and reputation of private schools in society and Public school teachers are more satisfied by their employments and salaries as compared to private school's teachers, whereas private school teachers have an advantage of more satisfaction in teaching their favorite subjects.Similarly, the Public schools are better regarding maintenance of school record as compared to private schools and the private schools have lead in administration, teacher's performance, home work schedule, school discipline, availability of physical facilities, planning of co-curricular activities, and better academic achievement of students as compared to public schools. Parents relating to private schools are more satisfied toward performance of private schools as compared to parents concerned to public school. Private school's children are more satisfied by regarding cooperation of their teacher with them, by teaching method of teachers, their encouragement through competition. The children of private school go to school happily whereas public school students are not satisfied with their schools and want to change the schools.

\section{Research Methodology}

\section{Research Design}

The purpose of a research design is to provide a plan of study which assessment of cause and effect relationships between independent and dependent variables. The present research uses both the qualitative and quantitative approach for the descriptive analysis of the existing phenomenon.

\section{Sampling Technique and Data Collection}

Looking at the geographical situation of the Chitwan District, the present study of institutional schools of Chitwan District categorizes into three sectors namely Eastern Chitwan, Middle Chitwan and Western Chitwan so as to cover entire district. Purpose of this category is to find out the real pictures of entire schools and their performance. There are 154 institutional schools in Chitwan district. Among 154 schools, 18 schools are selected from the schools of rural, semi-urban and urban area of Chitwan district.

Primary sources are used for collection of data of institutional schools of Chitwan district. The main purpose of collecting primary data and information at micro level is to understand 
academic environment, income and employment situation, perception of teachers, students and parents of the school, physical and academic facilities with the school and income status of sample schools. A structured questionnaire is prepared to collect the data from the respondents.

To describe the employment, income and characteristics of institutional schools' descriptive statistics are used. In some cases, simple tabular form in percent basis techniques are used to describe the relation between related variables.

\section{Empirical Results}

This chapter thoroughly analyzes the employment and income generated by the private schools.

\section{Qualification of Teacher}

The academic qualification of the teacher plays vital role in performance of the school as well as the economic and social development. More educated society is considered as a more developed society. Literacy rate and educational status of the people is one of the indicators of this.

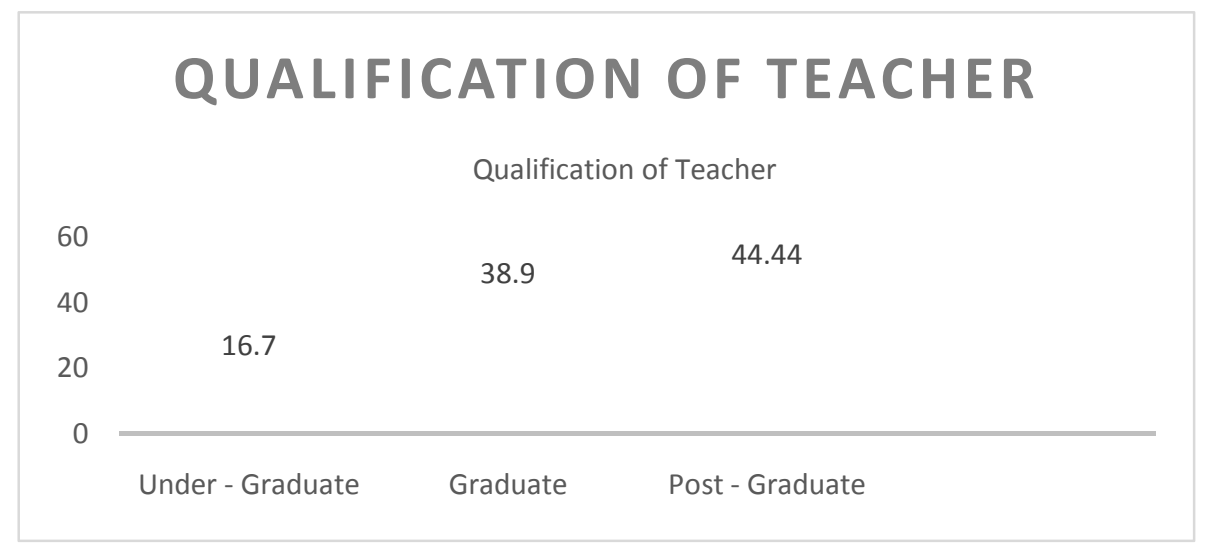

Out of the total 36 teachers surveyed.among them, 44.4 percent teachers are post graduate followed by 38.9 percent are graduate and rest 16.7 percent are under graduated. This distribution of more number of post graduate and graduate teachers in the school indicate that the development of the Chitwan district is also supported by the teachers working in the institutional schools.

\section{Salary Structure in Sample School}

Payment to the knowledge worker is key factor to motivate the knowledge workers. The tendency of leaving is seen to be directly proportional to the salary. It is obvious 
institutional schools are providing employment but there are one or more issues of exploitation paying unfair salaries.

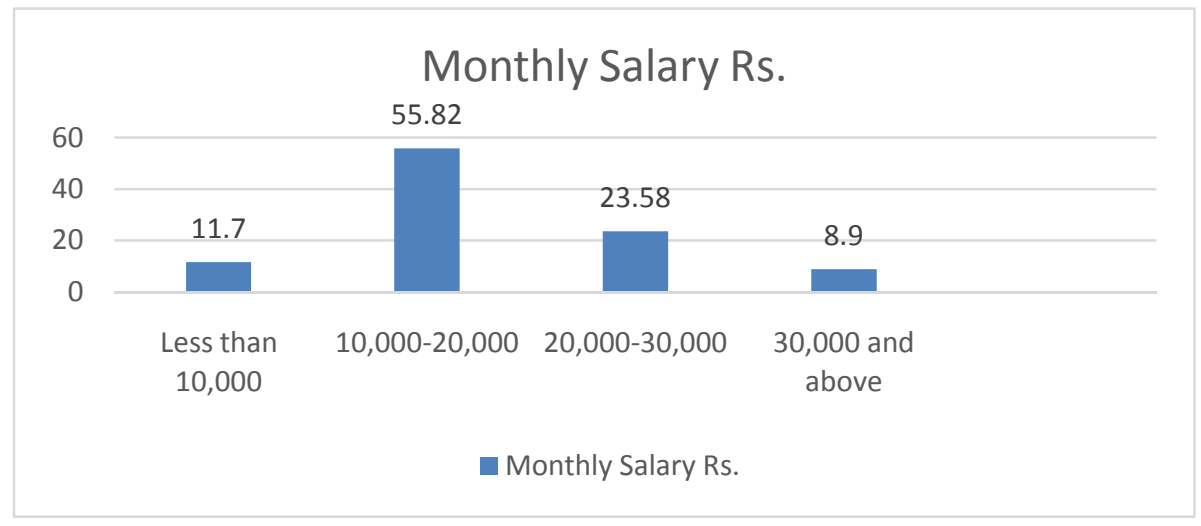

The maximum58.82 percent of teachers are getting salary Rs. 10,000-20,000 followed 11.7 percent less than Rs. 10,000, 23.58 percent Rs. 20,000-30,000, and the least 8.9 percent more than Rs. 30,000 respectively.

\section{Annual Average Income of Sample School}

Most of the private schools are profit motives. There are various income headings of private schools. Some of the heading gives more income and some gives very less. Monthly tuition fee is one of the major sources of income of institutional schools.

\begin{tabular}{|c|c|c|}
\hline \multicolumn{3}{|c|}{$\begin{array}{c}\text { INCOME OF PRIVATE } \\
\text { SCHOOL }(\%)\end{array}$} \\
\hline \multirow{5}{*}{$\begin{array}{ll} & 5.56^{5.83} 1.8 \\
4.87 & \end{array}$} & 18.64 & Admission fees \\
\hline & & Monthly Tuition Fee \\
\hline & & Exam Fee \\
\hline & & Computer/Lab fee \\
\hline & & Transportation Fee \\
\hline 63. & & Miscellaneous \\
\hline
\end{tabular}

Source : Field Survey, 2017

Out of the total annual income of the private school's 63.30 percent is covered by monthly tuition fee followed by annual and admission fee which is 18.64 percent of the total income. Computer/Lab fee5.56 and transportation fee cover5.83percent. Exam fee covers 4.87 
percent of total income. Miscellaneous covers very less which is only 1.80 percent of total income of the sample institutional schools. The payment made by the guardians as a tuition fee of their children plays significant role for the institutional schools.

\section{Average Annual Expenditure of Sample Schools}

There are various headings of the expenditure for institutional school. The income of the school itself depends upon how they minimize their expenditure.

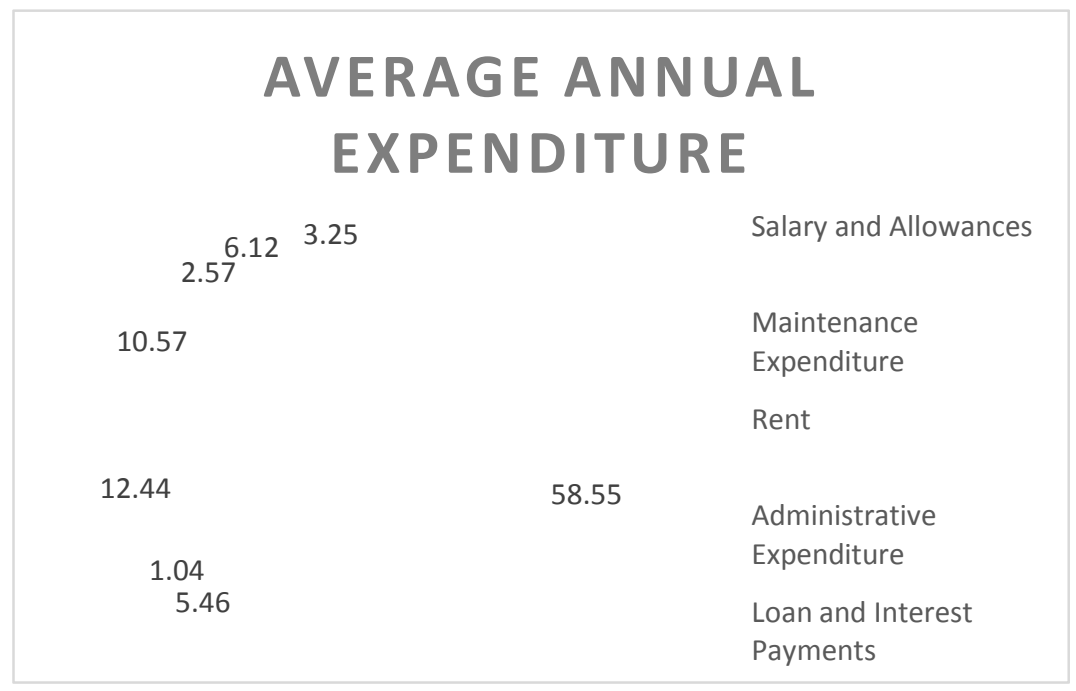

Source: Field Survey, 2017

Out of total 18 schools survey it was found that 58.55 percent of the expenditure goes as salary and allowances of teaching and non-teaching staffs and followed by 12.44 percent expenditure on administrative activities. There is 10.57 percent expenditure in loan and interest payment and 5.46 percent expenditure on repair and maintenance. Transportation is another major component of expenditure covering 6.12 percent of the total expenses. This information clearly indicates that major portion of the income of the institutional schools goes as a salary and allowances.

\section{Conclusions}

The role of private education has grown, and private education is being promoted and explored by some educational actors as a solution to the lack of sufficient public provision of education or underperforming public schools in Nepal.Most of the teachers working in institutional schools are either graduate or post graduate because of this qualification of teachers, the education status of the schools are also better and hence they are better educating children. There are significant numbers of semi-skilled and unskilled labor force 
in institutional schools providing employment not only to the skilled and educated mass but also to the unskilled and semi-skilled both male and female workers.

Majority of income of the school earns from fees goes to the salary of staffs. Though the saving and profit of the school is sufficient to cover the bank interest, it is not enough to pay back the bank loan. Hence, the majority of schools hasnot been able to build new infrastructures by both physical and non-physical (academic) so as to developed teaching learning environment.

\section{Acknowledgements}

I am thankful to TUTA, Patan Multiple Campus unit to publish the article in the journal of Patan Pragya.

\section{References}

Adhikari, D. B., \& Aryal, G. N. (2018). Factors Determining Performance of Institutional Schools in Chitwan, Nepal. Economic Journal of Development Issues, 1-11.

Ashley, L. D., Mcloughlin, C., Aslam, M., Engel, J., Wales, J., Rawal, S., ... \& Rose, P. (2014). The role and impact of private schools in developing countries-bibliography and literature reviews.

Alghanim, A. (1990). The status of private of education at Kuwait in perspective of parents. Unpublished Doctoral Dissertation, University of Kuwait.

Gibson, M.W. (1993). The motivation of suburban Milwaukee parents in choosing private elementary schools for their children. Unpublished doctoral dissertation, University of Wisconsin-Madison.

Lindahl, A. B. (2008). Does school privatization improve educational acheivement evidence from Sweden voucher reform. European Journal of Research on Education .

Ministry of Education (2016). School Sector Development Plan, Nepal, 2016-2023. Kathmandu: MoE, Gon.

Ministry of Education (2010). Monitoring, evaluation and supervision.MoE, Government of Nepal.

Shabbir, M., Wei, S., Guang, Y., Chong, R., Marwat, M. A., Nabi, G. and Bilal, A. (2014). A Comparative Study of Public versus Private Primary Schools: An Evidence from Azad Kashmir (Pakistan Administrative Kashmir). Journal of Education and Practice.

Yildirin, M. (2013). Effects on privatization in education quality and equilty comparision of public and private primary school in turkey.European Journal of Research and Association. 